\title{
Clinical Practice of Palliative Care: Current Concepts and Future Perspectives
}

\author{
Ashok Kumar Saxena ${ }^{1}$ Anupriya Saxena ${ }^{1}$ Anand Kumar Chopra ${ }^{1}$ Hazel Talwar ${ }^{1}$ Megha Bajaj \\ Nitika Yadav ${ }^{1}$
}

${ }^{1}$ Department of Anaesthesiology and Pain Medicine, University College of Medical Sciences, University of Delhi and GTB Hospital, Delhi, India

\begin{abstract}
Address for correspondence Ashok Kumar Saxena, MD, DA, FICA, FAMS, Department of Anaesthesiology and Pain Medicine, University College of Medical Sciences, University of Delhi and GTB Hospital, Delhi 110095, India (e-mail: profashoksaxena2@gmail.com).
\end{abstract}

\begin{abstract}
Pain is a distressing symptom having biological, psychological, and social consequences. A large number of cancer patients are in advanced stages of the disease and for these patients the only positive and realistic option is pain management and palliative care. These patients have complex needs that have to be taken care of in order to improve the quality of life of such patients and their family members. Surgical treatment along with chemotherapy and radiotherapy is the mainstay for the treatment of cancer, but these modalities also have limitations. The main aim behind palliative care is to allay the sufferings of a terminally ill patient by responding to pain using multimodal analgesia including opioids. According to WHO step ladder, other symptoms like breathlessness, fatigue, delirium etc., are also needed to be managed adequately along with psychosocial and spiritual support. Along with it patients and his family members should be well explained that palliative care is a multidimensional approach directed to the best possible care for that stage of their illness, which may not be

Keywords

- palliative care

- clinical practice

- current concepts curative in nature. There are multiple obstacles in the growth of palliative care in India. Nonetheless we have overcome many such hurdles and there has been a noticeable change regarding palliative care in the mindset of health care providers in the last 2 decades.
\end{abstract}

\section{Introduction}

WHO defined palliative care "as an approach that improves the quality of life of patients and their families facing the problem associated with life threatening illness, through the prevention and relief of suffering by means of early identification and impeccable assessment and treatment of pain and other problems: physical, psychosocial, and spiritual."1,2

Palliative care is for everyone and anyone during any stage though mostly terminal stage of a serious ailment. It can also be planned concurrently with surgical excision or chemotherapy or radiotherapy or all three combined together. Obviously it includes hospice care services and is surely not having any relationship with prognosis. ${ }^{3}$

The palliative care is required in number of terminal diseases. The transition between the aggressive treatment to cure or to prolong a good quality of life and palliative care may not be clear and both should be considered in conjunction, each becoming dominant at a given time.

Palliative care is an interdisciplinary approach involving physician, nursing staff, social workers, priest/father of church and various other specialties that focus on enhancing the quality of life for patients of any age, who are living with any critical illness and also their families. Patients receiving palliative care can have various types of symptoms like breathlessness, delirium, nausea, vomiting, constipation, respiratory infection, pain, which need to be addressed individually and patiently. ${ }^{4}$

Palliative care and concepts of "hospices" are nothing new to the western world and is already very well established in the western hemisphere, but in developing nation like India it is very much in infancy, may be because developing nations 
have huge challenges to first manage communicable diseases like malaria, dengue, swine flu, enteric fever, etc.

In India the palliative care is getting established with whatever limited support that has been provided by the government of India. On the other hand, the only state and the very first state where it got established almost a decade back was state of Kerala, which has set an important benchmark for other states in India to follow. ${ }^{5}$

Heart disease, respiratory diseases, diseases of digestive system and alcohol-related diseases such as liver problems or cancer, homeless populations, prisoners, sex workers, and individuals with substance use disorders have been cited as major chronic diseases causing morbidity and mortality among patients. ${ }^{6,7}$

\section{Historical Aspects of Palliative Care}

The pioneering works of Dame Cicely Saunders in the United Kingdom drew the attention of the Medical Community and the public to the evolution of palliative care in 1967. She framed an ideal model of care for the patients suffering from terminal cancer and who are close to death. She has been the role model and great source of inspiration for various health care providers involved in the setting up of palliative care units. The first hospital palliative care team was established in St. Thomas Hospital in London in 1977. Since then rapid progress has been made in developing palliative care as a discipline in the health care delivery. ${ }^{8}$

In India the earliest centers for delivery of palliative care were established in few places like Ahmedabad, Bangalore, Mumbai, Kerala state in the late 1980s and early 1990s. In other states palliative care was initiated with the opening of pain clinic and palliative care services under the department of anesthesiology. Now the Kerala network has more than 60 units covering a population greater than 12 million and is one of the largest networks in the world. ${ }^{9}$

Palliative care in India is still at an early stage of development and is facing numerous challenges. It is estimated that less than 3\% or may be more of India's cancer patients have access to adequate pain relief. ${ }^{10}$ The government of India initiated a National Cancer Control Program in 1975, modified in 1984 , to make pain relief one of the basic services to be provided at primary health care level. This policy was however not translated into a large scale service provision. Access to the availability of opioid and other drugs is the most important practical issue in the establishment of palliative care in India.

Approximately $30 \%$ of the world population suffers from pain. Pain survey's reliable estimates indicate that the chronic pain prevalence is somewhat closer to $19.3 \%$ in India. ${ }^{11}$ In a study conducted by Dureja and Saxena et al, they concluded that the overall point prevalence of chronic pain in India was $13 \%$, and the mean intensity of pain on numeric rating scale scale was 6.93 in India. ${ }^{12}$

There has been a steady progress in the field of palliative care in the past few years. According to a report by Worldwide Hospice Palliative Care Alliance, India has moved from Group 2 countries (making capacity to building activities) to Group 3B for having generalized palliative care provisions.
Diversity and complexity of health problems pose challenges in access to good palliative care more so in people experiencing homelessness. ${ }^{13}$

\section{Evaluation and Management of Common Physical Symptoms}

\section{Pain}

Pain is a very prominent and distressful symptom in patients presenting at the end of life. The effective relief of pain in a palliative patient depends mainly on a comprehensive assessment to identify the different physical, psychological, social, and spiritual aspects that are specific to each patient, and optimally intervene on a multidisciplinary level.

Cancer pain is a greatly feared symptom in all the patients. A recent meta-analysis reported pooled prevalence rates of $55 \%$ for cancer-related pain in patients who were receiving disease modifying treatment and $64 \%$ in those with advanced metastatic or terminal disease.${ }^{14}$ An accurate, thorough, and systematic assessment of cancer pain is crucial to identify the underlying etiology and decide a treatment plan. For cancer pain management, we need to know the cancer patient's life expectancy and the exact staging of the cancer pathology. In case the survival chances are low and life expectancy is not much, one can have the freedom of taking higher degree of risks for providing optimum pain relief. On the other hand, if chances are bright for recovery or subsiding of cancer pathology, then spiritual, psychological, and cognitive support and steps for enhancement of quality of life should be undertaken.

Metastatic disease most commonly occurs in the bones, lungs, and liver. Therefore these patients would have pain which may be located at multiple areas of the body including the pain due to bone metastasis or of neuropathic origin. ${ }^{15,16}$ Ineffective pain relief further worsens the cancer burden.

Palliative care involves assessing and managing pain that is persistent, may have multiple etiologies, one or more of which are incurable, is impairing function, increasing dependency, and invokes fear of further suffering and death. The pain must be assessed in detail to know which component of pain prevails in a particular patient. Pharmacological management is one of the main modality for the treatment of pain. The choice of pharmacological agent depends on the primary pathology of the patient as well as underlying comorbidities as all the medications have different action and potential side effects. Along with it there is variability between patients in terms of response to a particular drug.

A thorough assessment of pain in palliative care helps in the development of strategies to manage the pain and enhance quality of life. These may include: (1) regular analgesic administration according to the WHO analgesic ladder; (2) use of appropriate pharmacological and nonpharmacological adjuvant therapies; (3) a wide range of strategies to improve mood, morale, general health, and resilience; and (4) open discussions about pain and sufferings to assist in appropriate pain interpretation.

WHO Analgesic ladder: The WHO analgesic ladder is a method to guide symptomatic pain relief ${ }^{17}$ ( - Fig. 1). 


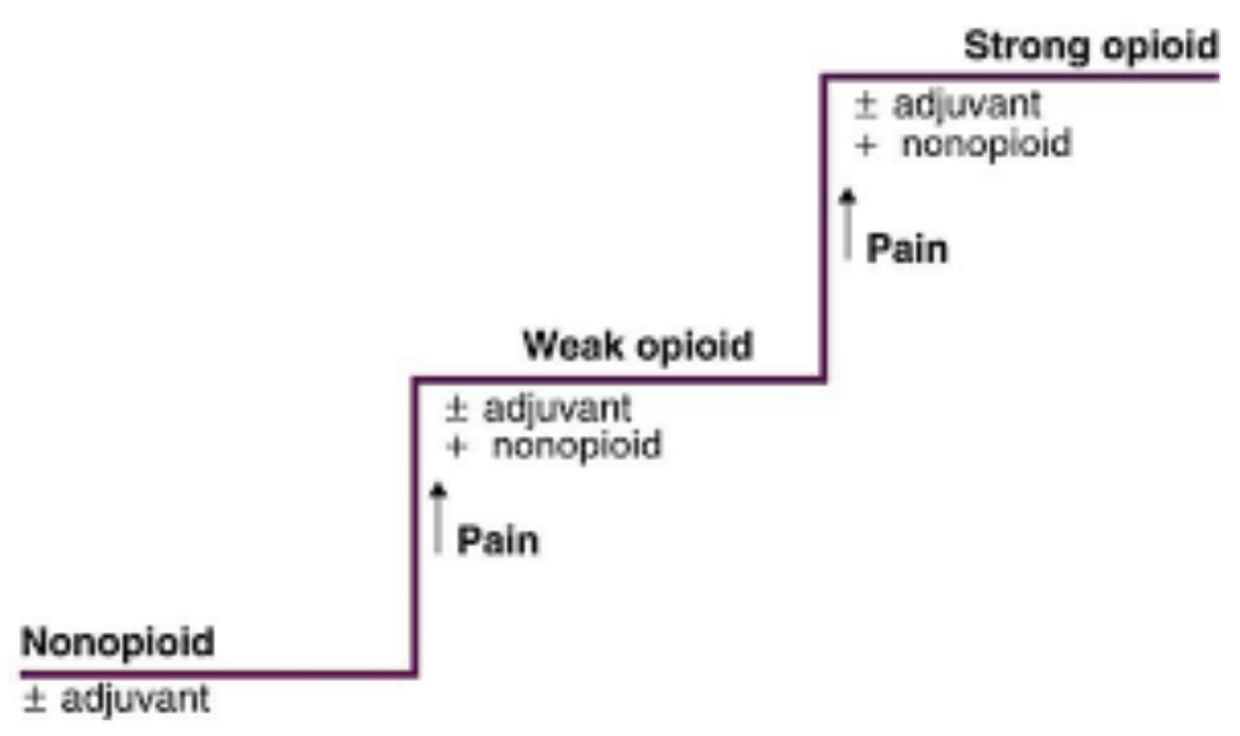

Fig. 1 Three step analgesic ladder (fourth step is interventional pain management).

Step 1: Nonopioid \pm Adjuvant.

Step 2: Weak opioid + nonopioid \pm adjuvant.

Step 3: Strong opioid + nonopioid \pm adjuvant.

Step 4: Interventional/neurolytic pain procedures.

A nonopioid is used for analgesia in the first step of the ladder. This is usually paracetamol at a dose of 1 gram every 6 hours. If it is not effective at this dose we move to Step 2. For Step 2, a weak opioid such as codeine is added to the analgesic used in Step 1 . This usually means adding codeine to the regular paracetamol already being taken. The recommended dose of codeine is 30 to $60 \mathrm{mg}$ every 4 hours up to a maximum of $240 \mathrm{mg}$ daily. In the Step 3, among the strong opioids morphine remains the "gold standard" as it has been the most extensively studied, and is available in a wide range of formulations and routes.

If peroral use of oral opioids is not possible then it can be administered transdermally, for example, transdermal fentanyl patch ( $25 \mu \mathrm{g} / \mathrm{h}, 50 \mu \mathrm{g} / \mathrm{h}$, etc.) and transdermal buprenorphine patch $(5 \mathrm{mg} / \mathrm{h}, 10 \mathrm{mg} / \mathrm{h})$. Another option is that of subcutaneous infusion of opioids. For the management of breakthrough pain, intranasal fentanyl sprays or buccal fentanyl tablets or sublingual tablets can be utilized. ${ }^{18}$ For an adult who has pain on the regular weak opioid used in Step 2, an appropriate starting dose of oral morphine is $5 \mathrm{mg}$ every 4 hours. Later sustained release preparations can also be used. Laxatives are generally prescribed along with morphine to avoid constipation caused mainly through peripheral opioid receptor. ${ }^{19}$ Other side effects associated with the use of opioids are nausea, vomiting caused by direct stimulation of the chemoreceptor trigger zone, or the vestibular apparatus and through the inhibition of gut motility. ${ }^{20}$

Most opioids are metabolized in the liver by glucuronidation and/or demethylation catalyzed by cytochrome P450 isoenzymes. It is administered carefully in patients with renal impairment due to one of its active metabolites, M3G, which is dependent on kidney for excretion and hence may lead to opioid-related toxicity. So in patients with compromised renal function lipophilic opioids that do not have active metabolites (e.g., fentanyl) should be considered. Hydromorphone and oxycodone are also to be used with caution followed by close monitoring of the patient. ${ }^{21,22}$

Long-term usage of opioids in cancer pain may produce hypogonadism and hyperprolactinemia which may ultimately lead to fertility problems. Long-term use may also predispose to chronic fatigue and osteoporosis due to hormonal changes. ${ }^{23-25}$ In cases where long acting preparations and opioids with immunosuppressive properties (e.g., morphine) were used the incidence of infection and hospitalization was higher. ${ }^{26}$ Components of $\boldsymbol{-}$ Fig. $\mathbf{2}$ can be very well utilized in cancer pain patients while prescribing them on opioid therapy. Few of the screening tools like opioid risk tool, risk efficacy and screener and opioid assessment for patient with pain revised can be brought into practice to elicit some amount of information as monitored in - Fig. $2 .{ }^{27}$ The dose of opioids shall be on the higher side if the intensity of cancer pain increases or there is a fresh development including the addition of neuropathic component in cancer pain or if the patient is cachectic (so the bioavailability of the opioid goes down or if there is a possibility of drug interaction) ${ }^{28}$ Requirement for increased doses of opioids may also reflect opioid tolerance or opioid-induced hyperalgesia. This can be managed by altering the opioid or its route of administration or by adding ketamine.

Caraceni et al have brought out revised evidence-based recommendation on behalf of the European Association for palliative care for the relevant use of various opioids in the management of cancer pain. ${ }^{30}$

Opioids have been combined with antidepressants or antiepileptic drug in tumor-related cancer pain. A recent systematic review concluded that these combination did not significantly improve pain relief compared with monotherapy. ${ }^{31}$ 


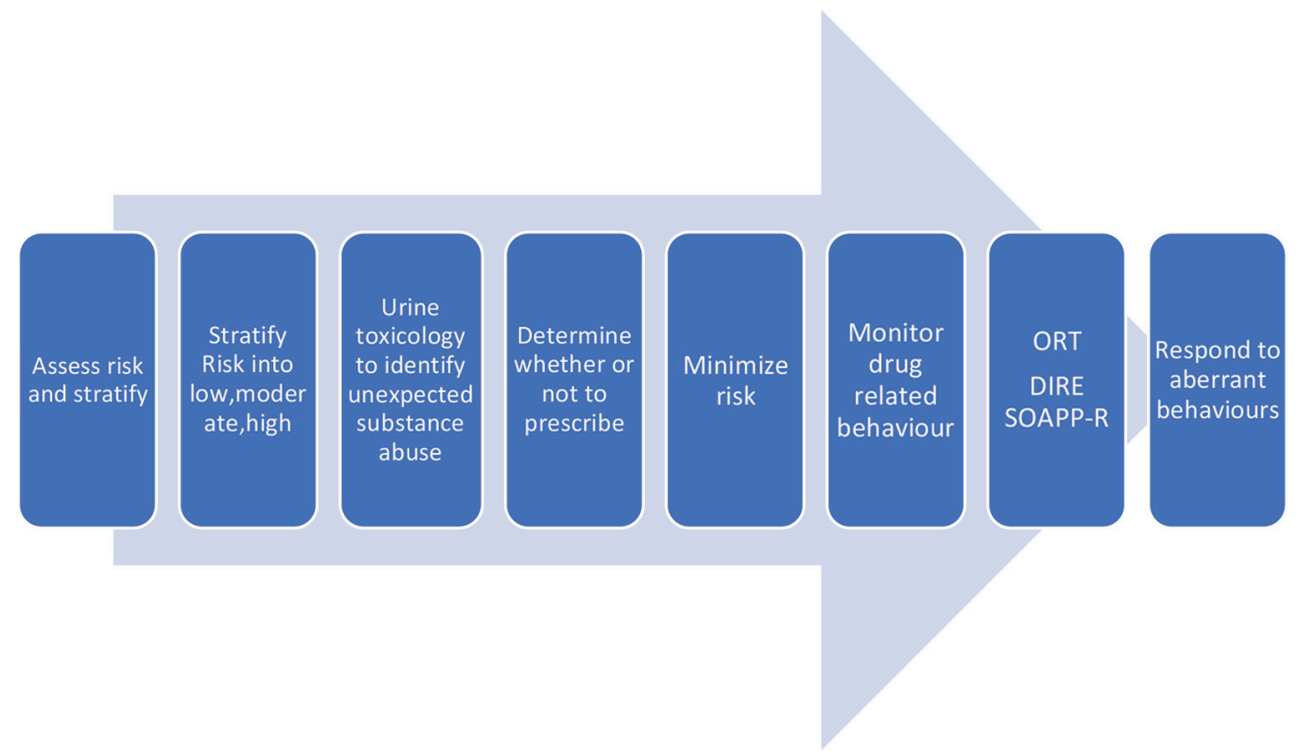

Fig. 2 Basic components for monitoring cancer pain patients who are on opioids. ${ }^{29}$

\section{Adjuvants}

These medications have effects on specific types of pain syndromes, such as neuropathic or inflammatory pain. Examples are antidepressants and antiepileptic drugs. Tricyclic antidepressants for example amitriptyline, duloxetine, and venlafaxine are commonly used. Anticonvulsants such as gabapentin and pregabalin are used for pain control as well. Amitriptyline is effective in the dose range of 10 to $75 \mathrm{mg} / \mathrm{d}$ especially for targeting the neuropathic component of cancer pain. Their anticholinergic effects are the main side effects. Recently duloxetine and venlafaxine have also been used for neuropathic component of cancer pain. Duloxetine has no anticholinergic effect but may produce nausea, vomiting, and is especially beneficial for elderly patient. ${ }^{32}$

Gabapentin and pregabalin inhibit voltage-gated calcium channels. They have strong affinity for alpha 2 delta 1 receptors located on voltage-gated calcium channels. They are mainly excreted by renal route hence dosage needs to be adjusted according to creatinine clearance rate and they have no known drug interaction and on long-term use they may produce gain in body weight. Oral gabapentin is administered in the dose range of 300 to $3,600 \mathrm{mg} / \mathrm{d}$ in three divided doses, though in Indian patients usually the upper limit is $1,800 \mathrm{mg} / \mathrm{d}$. Oral pregabalin is administered in dose range of 75 to $600 \mathrm{mg} / \mathrm{d}$ in two divided doses, though in Indian patient population the upper limit is 300 to $450 \mathrm{mg} / \mathrm{d} .^{33}$

Corticosteroids are prescribed in a variety of clinical conditions where inflammation is causing pain such as neuropathic pain, cerebral edema, spinal cord compression, bone or visceral pain. Long duration therapy should be avoided

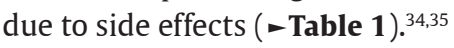

Interventional pain management should be considered as adjunct to comprehensive medical management in intractable cancer pain patients. The neuroablative procedures involve the use of chemical agents (alcohol 50-100\% and freshly prepared phenol 6-10\%), heat (radiofrequency), cold (cryoablation), compression, and surgery. ${ }^{36}$ Neurolytic blockade of peripheral nerves produces short-term pain relief. Intercostal neurolysis has a median duration of 3 weeks. ${ }^{37}$ Other options are percutaneous cervical cordotomy and radiofrequency ablation. It reduces perception of temperature in addition to pain. Its value in mesothelioma is well documented. ${ }^{38}$ Continuous programmable intrathecal pumps containing preservative-free morphine, with or without clonidine are also used but their cost is highly exorbitant. ${ }^{39}$

\section{Nonpharmacological Methods of Pain Management}

Nonpharmacological modalities can be used with a pharmacological approach to pain management. These strategies can be very effective in relieving pain and providing comfort while empowering the patient and family to deliver pain relief in a safe manner. Nonpharmacological modalities include, but are not limited to, relaxation techniques, superficial heating or cooling, acupuncture, TENS and spiritual support, and pacing. ${ }^{40}$

Recently the frequency of palliative chemotherapy and the rate of invasive procedures have increased in patients with end-stage gynecologic cancer who were treated aggressively without hospice management over 2011 to 2015 as compared to previous years. ${ }^{41}$

Neuropathic component of cancer pain is still a serious problem affecting day to day life of cancer patients because of the wide variety of underlying causes and the paucity of clear data for its diagnosis and treatment. With the advancement in palliative care in the form of new technologies and therapies, cancer patients have a longer survival; so symptoms like neuropathic pain need to be well treated to improve the quality of life of these patients.

According to International Association for study of Pain (IASP) neuropathic pain is defined as the pain arising from a lesion or disease affecting the somatosensory system. ${ }^{42}$ Neuropathic pain manifests as a regional distribution of pain 
Table 1 Pharmacokinetic information for opioids, antidepressants, and gabapentinoids in managing neuropathic component of cancer pain 29

\begin{tabular}{|c|c|c|c|}
\hline Drugs & Metabolic pathway & Active metabolite & Remarks \\
\hline \multicolumn{4}{|l|}{ Opioids } \\
\hline Buprenorphine & CYP3A4; UGT 1A1/1A3 & Norbuprenorphine & \\
\hline Fentanyl & CYP3A4 & No & \\
\hline $\begin{array}{l}\text { Hydromorphone } \\
\text { (not available in India) }\end{array}$ & UGT 1A1 & No & $\begin{array}{l}\text { Creatinine clearance rate } \\
(C C R) \text { to be monitored }\end{array}$ \\
\hline $\begin{array}{l}\text { Methadone } \\
\text { (not available in India) }\end{array}$ & CYP 1A2/2B6/2C19/2D6/3A4 & No & $\begin{array}{l}\text { QT-time long and variable } \\
\text { half-life }\end{array}$ \\
\hline Morphine & UGT 1A1/2B7 & M6G & Accumulation in kidney failure \\
\hline $\begin{array}{l}\text { Oxycodone } \\
\text { (not available in India) }\end{array}$ & CYP 3A4/2D6 & Oxymorphone & $\begin{array}{l}\text { CCR to be monitored. CYP3A4 } \\
\text { inducers reduce and inhibitors } \\
\text { increase effect }\end{array}$ \\
\hline \multicolumn{4}{|l|}{ Antidepressant } \\
\hline Amitriptyline & CYP 2D6/2C19/3A4 & Nortriptyline & $\begin{array}{l}\text { Single nucleotide } \\
\text { polymorphism }\end{array}$ \\
\hline Nortriptyline & CYP2D6 & 10-Hydronortryptyline & $\begin{array}{l}\text { Single nucleotide } \\
\text { polymorphism }\end{array}$ \\
\hline Duloxetine & CYP2D6/1A2 & No & $\begin{array}{l}\text { Single nucleotide } \\
\text { polymorphism }\end{array}$ \\
\hline $\begin{array}{l}\text { Venlafaxine } \\
\text { (not available in India) }\end{array}$ & CYP2D6 & o-Desmethyl venlafaxine & $\begin{array}{l}\text { Single nucleotide } \\
\text { polymorphism }\end{array}$ \\
\hline \multicolumn{4}{|l|}{ Gabapentinoids } \\
\hline Gabapentin & No liver metabolism & No & CCR to be monitored \\
\hline Pregabalin & No liver metabolism & No & CCR to be monitored \\
\hline
\end{tabular}

along a peripheral innervation. Patients may describe this pain as burning, prickling, tingling, or they may have unusual sensations ranging from numbness to lancinating sensations. Using combinations of drugs with different mechanisms of action may provide effective treatment. ${ }^{43,44}$

\section{Breathlessness}

Breathlessness is common in people with advanced cancer or cardiorespiratory or neurological disease. It generally occurs by complex interaction among chest walls, lungs, upper airways, and central nervous system. Once reversible causes have been addressed, management focuses on nonpharmacological interventions, aimed at increasing comfort. Pharmacological treatment includes low dose morphine, and if appropriate, benzodiazepines (if anxiety) or oxygen treatment (if hypoxemic). The effectiveness of treatments will vary between patients, so a flexible approach to management is required ( - Table 2 ).

Nonpharmacological strategies ${ }^{46}$ targeted to improve the comfort of palliative care patient include the following:

- Altering the position of the patient to the maximum comfortable position, for example, elevating the head and trunk, or lying with the affected lung downward if only one lung is pathological to decrease ventilation perfusion mismatch.

- Chest physiotherapy and deep breathing exercises.
- Cognitive behavioral therapy ${ }^{47}$ in the form of relaxation exercises.

- Using a humidifier.

- Decreasing room temperature.

- Elimination of irritants such as smoke or allergens which further irritate the airway.

- Opening a window for ventilation.

Table 2 Reversible causes and their relevant management of breathlessness ${ }^{45}$

\begin{tabular}{|l|l|}
\hline Anemia & Blood transfusion \\
\hline Acidosis & $\mathrm{HCO}_{3}$ \\
\hline Bronchospasm & Bronchodilator therapy \\
\hline Pneumonia & Antibiotic therapy \\
\hline Pulmonary embolus & Anticoagulate \\
\hline Pneumonitis & Steroids \\
\hline Atrial fibrillation & Antiarrhythmic \\
\hline Congestive cardiac failure & Diuretic \\
\hline Pericardial tamponade & Drainage \\
\hline $\begin{array}{l}\text { Carcinomatous } \\
\text { lymphangitis }\end{array}$ & Steroids \\
\hline Lung metastases & $\begin{array}{l}\text { Chemotherapy/hormonal } \\
\text { therapy }\end{array}$ \\
\hline
\end{tabular}


- Providing a window to see outside has a positive impact on the patient.

- Positive counseling and reassurance.

Systemic opioids (oral morphine) are safe and effective treatment for breathlessness in advanced stages of chronic obstructive pulmonary disease patients. Low dose benzodiazepines can be used as an adjuvant therapy to allay anxiety. Oxygen is not administered universally to all patients with breathlessness; only patients with established hypoxemia $\left(\mathrm{PaO}_{2}<55 \mathrm{~mm} \mathrm{Hg}\right)$ are likely to benefit by oxygen therapy. Benefits of oxygen therapy in a hypoxic patient are reduction of hypercapnia and polycythemia thus leading to better sleep and comfort for the patient. ${ }^{48}$

In patients who are not significantly hypoxemic, there is currently no evidence that oxygen reduces breathlessness. ${ }^{49}$

A Cochrane review found no overall improvement in breathlessness among patients with cancer using oxygen; however, some individuals felt better breathing oxygen. ${ }^{50}$

Malignant pleural effusion is also a leading cause of breathlessness. For treatment of malignant pleural effusion, recently Bhatnagar et al observed that with an indwelling pleural catheter along with talc administration, there are greater chances of pleurodesis. ${ }^{51}$

\section{Fatigue}

Fatigue may be defined as "a subjective, unpleasant symptom which incorporates total body feelings from tiredness to exhaustion, creating an unrelenting overall condition which interferes with a person's ability to function to their normal capacity." It has a major impact on the quality of life of the patient. ${ }^{52}$

There is no single preferred assessment tool but for clinical purposes a numerical scale can be followed. This can be a numerical 0 to 10 scale or fatigue scoring system based on palliative care assessment tool as described below ${ }^{53}$ :

1 : no fatigue.

2: fatigue present but not affecting daily life.

3: fatigue present and having moderate effect on daily life.

4: fatigue present and having overwhelming effect on daily life.

Treatable cause of fatigue must be managed first, for example, anemia, infection, drug side effect, insomnia, and depression. Drug management of fatigue may include the use of corticosteroid, psycho stimulants, or antidepressants. ${ }^{54}$

Nonpharmacological measures in the form of physiotherapy, psychological support, occupational therapy can always be used.

\section{Psychological Symptoms like Delirium, Confusion, Anxiety, and Depression}

Delirium is one of the common and most serious neuropsychiatric symptom seen in terminally ill patients. It is associated with high degree of morbidity and stress both for the patient and the family members. In Cochrane database of systemic review, delirium is described using a variety of terms such as agitation, acute confusional state, encephalopathy, organic mental disorders, and terminal restlessness. ${ }^{55}$
In a recent study by Bush et al, the authors observed the incidence of delirium and associated symptoms from $43 \%$ in general cancer population to $85 \%$ in the patients in terminal stage of their illness. ${ }^{56}$

According to Cherny et al, three clinical subtypes of delirium described are as follows ${ }^{45}$ :

1. Hyperactive subtype-hyperaroused, hyperalert, agitated.

2. Hypoactive subtype-hypoaroused, hypoalert, or lethargic.

3. Mixed with alternating features of both.

Common precipitating events include sepsis, medication side effects, and metabolic aberrations (particularly hypercalcemia, hyponatremia, uremia, dehydration, brain metastases, or cerebrovascular events).

Pain physicians always face the dilemma to intervene in reversing delirium, and according to Yennurajalingam et al following are the components of a possible strategy to be adopted to manage delirium ${ }^{57}$

- Identify the underlying cause (if possible) and assess its impact on the patient's quality of life.

- Rank the distress of delirium in the context of the patient's overall symptom complex.

- Assess the potential problems associated with correcting the underlying causes and consequent impact on the quality of life (e.g., using intravenous line for antibiotics and patient pulling out).

- Consider the advantages and disadvantages of intervention versus no intervention.

- One must discuss the treatment options with the palliative care patient (if mild cognitive impairment) and the family, to allow informed decision-making and ultimately the development of a consensus on the appropriate level of intervention.

Various medications for the management of agitation and delirium in the end stage of the disease include antipsychotics of newer class such as olanzapine $5 \mathrm{mg}$, quetiapine, and aripiprazole.

They tend to have lesser extrapyramidal side effects than earlier generation antipsychotics such as haloperidol, chlorpromazine, levomepromazine, or risperidone. In addition, benzodiazepines may be needed for faster control of agitation and anxiety.

\section{Spiritual Support}

The philosophy and practice of palliative care operate upon an understanding of a person as a whole along with his disease. It is reflected in the multidimensional approach of the biopsychosocial model. One cannot provide whole-person care without giving consideration to the relevant spiritual needs held by the patients with serious illness. Palliative care providers are also called to be advocates for the spiritual and religious rituals of patients and families, especially at the time of death. ${ }^{58}$

As defined by the Hospice and Palliative Nurses Association, "spiritual distress refers to a disruption in one's beliefs of value system, a shaking of one's basic beliefs." 59 
Anandarajah and Hight observed that "spiritual distress and spiritual crisis" occur when a person is "unable to find sources of meaning, hope, love, peace, comfort, strength, and connection in life or when conflict occurs between their beliefs and what is happening in their life." ${ }^{60}$

\section{Conclusion}

Overall management of cancer pain remains suboptimal even in the best possible center in a developed country, so one can imagine the status of palliative care in a developing country like India. There is no doubt that these patients keep suffering for a number of months and years due to a variety of causes, before they get any opportunity to finally visit a pain and palliative care center, where oral strong opioids are available or before a neurolytic interventional pain procedure can be offered. ${ }^{61}$ It is essential that timely and early referrals for cancer pain management are sent to pain and palliative care centers for achieving a satisfactory pain relief.

It has been suggested by Linklater et al and Kay et al that joint consultation clinics should be held between the department of palliative medicine and pain medicine, so that patients are assessed in depth and well managed as large number of procedures with wider dimension can be carried out than in those hospitals without these kinds of associations. ${ }^{62,63}$

Liaison between various specialties with specialists interested in cancer pain management (palliative care, oncology, radiotherapy, pain specialists, orthopedics and general surgery, etc.) will allow for a variety of palliative pain control options to be considered.

As of today, palliative care currently provided to the people experiencing homelessness does not meet the core requirements of palliative care due to bottlenecks regarding timely identification, care for the social network, and the assessment and management of physical symptoms and psychosocial and spiritual care needs.

Recently La Cruz et al concluded that patient education is of paramount importance and is intensively required to minimize stealing and inappropriate use and at the same time ensuring genuine access to opioids for real needy cancer pain patients in palliative care while taking steps to stop the entry of these drugs into the non-needful strata of the society. ${ }^{64}$

Today, we are 10 years ahead of the IASP Global Year against cancer pain (2008-2009) and still cancer pain management remains a mammoth task ahead; but integrating our efforts on palliative care, as mentioned above with the Indian holistic system (yoga, meditation, etc.) may optimally connect the mind, body, soul and shall go a long way in mitigating the pain and enhancing the quality of life of such patients.

\section{Conflict of Interest}

None declared.

\section{References}

1 Hugel H, Sharma ML. Cancer pain management: overview and personal perspective. Indian J Pain 2009;23:272-277
2 World Health Organisation, WHO definition of palliative care; 2002 Available at: http://www.who.int/cancer/palliative/ definition/en. Accessed August 8, 2017

3 Coelho CBT, Yankaskas JR. New concepts in palliative care in the intensive care unit. Rev Bras Ter Intensiva 2017;29(2):222-230

4 Twycross R, Wilcock A, Symptom Management in Advanced Cancer. Oxford: Radcliffe Medical Press; 2001;3:17

5 Kumar A. Organization and development of pain clinics and palliative care in developing countries. Eur J Anaesthesiol 2004;21(3):169-172

6 Aldridge RW, Story A, Hwang SW, et al. Morbidity and mortality in homeless individuals, prisoners, sex workers, and individuals with substance use disorders in high-income countries: a systematic review and meta-analysis. Lancet 2018;391(10117):241-250

7 Graham L, Fischbacher CM, Stockton D, Fraser A, Fleming M, Greig K. Understanding extreme mortality among prisoners: a national cohort study in Scotland using data linkage. Eur J Public Health 2015;25(5):879-885

8 Kelley AS, Morrison RS. Palliative care for seriously ill. N Engl J Med 2015;373(8):747-755

9 Khosla D, Patel FD, Sharma SC. Palliative care in India: current progress and future needs. Indian J Palliat Care 2012;18(3):149-154

10 Shanmugasundaram S, Chapman Y, O'Connor M. Development of palliative care in India: an overview. Int J Nurs Pract 2006;12(4):241-246

11 Saxena AK, Jain PN, Bhatnagar S. The prevalence of chronic pain among adults in India. Indian J Palliat Care 2018;24(4):472-477

12 Dureja GP, Jain PN, Shetty N, et al. Prevalence of chronic pain, impact on daily life, and treatment practices in India. Pain Pract 2014;14(2):E51-E62

13 Song J, Bartels DM, Ratner ER, Alderton L, Hudson B, Ahluwalia JS. Dying on the streets: homeless persons' concerns and desires about end of life care. J Gen Intern Med 2007;22(4):435-441

14 van den Beuken-van Everdingen MH, Hochstenbach LM, Joosten EA, Tjan-Heijnen VC, Janssen DJ. Update on prevalence of pain in patients with cancer: systematic review and meta-analysis. J Pain Symptom Manage 2016;51(6):1070-1090

15 Valeberg BT, Rustøen T, Bjordal K, Hanestad BR, Paul S, Miaskowski C. Self-reported prevalence, etiology, and characteristics of pain in oncology outpatients. Eur J Pain 2008;12(5):582-590

16 Jain PN, Chatterjee A, Choudhary AH, Sareen R. Prevalence, etiology, and management of neuropathic pain in an Indian cancer hospital. J Pain Palliat Care Pharmacother 2009;23(2):114-119

17 Vargas-Schaffer G. Is the WHO analgesic ladder still valid? Twenty-four years of experience. Can Fam Physician 2010;56(6):514-517, e202-e205

18 Vissers D, Stam W, Nolte T, Lenre M, Jansen J. Efficacy of intranasal fentanyl spray versus other opioids for breakthrough pain in cancer. Curr Med Res Opin 2010;26(5):1037-1045

19 Wiffen PJ, McQuay HJ. Oral morphine for cancer pain. Cochrane Database Syst Rev 2007;(4):CD003868

20 Porreca F, Ossipov MH. Nausea and vomiting side effects with opioid analgesics during treatment of chronic pain: mechanisms, implications, and management options. Pain Med 2009;10(4):654-662

21 Dean M. Opioids in renal failure and dialysis patients. J Pain Symptom Manage 2004;28(5):497-504

22 Niscola P, Scaramucci L, Vischini G, et al. The use of major analgesics in patients with renal dysfunction. Curr Drug Targets 2010;11(6):752-758

23 Birthi P, Nagar VR, Nickerson R, Sloan PA. Hypogonadism associated with long-term opioid therapy: a systematic review. J Opioid Manag 2015;11(3):255-278 
24 Dev R, Hui D, Del Fabbro E, et al. Association between hypogonadism, symptom burden, and survival in male patients with advanced cancer. Cancer 2014;120(10):1586-1593

25 Rajagopal A, Vassilopoulou-Sellin R, Palmer JL. Kaur G, Bruera E. Symptomatic hypogonadism in male survivors of cancer with chronic exposure to opioids. Cancer 2004;100(4):851-858

26 Dublin S, Walker RL, Jackson ML, et al. Use of opioids or benzodiazepines and risk of pneumonia in older adults: a population-based case-control study. J Am Geriatr Soc 2011;59(10):1899-1907

27 Koyyalagunta D, Bruera E, Aigner C, Nusrat H, Driver L, Novy D. Risk stratification of opioid misuse among patients with cancer pain using the SOAPP-SF. Pain Med 2013;14(5):667-675

28 Heiskanen T, Mätzke S, Haakana S, Gergov M, Vuori E, Kalso E. Transdermal fentanyl in cachectic cancer patients. Pain 2009;144(1-2):218-222

29 Kalso E, Paice JA, Cancer pain: current strategies for safe and effective relief. In: Gold MS, Pogatzki-zahn EM, Wallace MS, eds. Pain 2018: Refresher Courses. Washington, DC: IASP Press; 2018 187-195

30 Caraceni A, Hanks G, Kaasa S, et al. European Palliative Care Research Collaborative (EPCRC)European Association for Palliative Care (EAPC). Use of opioid analgesics in the treatment of cancer pain: evidence-based recommendations from the EAPC. Lancet Oncol 2012;13(2):e58-e68

31 Kane CM, Mulvey MR, Wright S, Craigs C, Wright JM, Bennett MI. Opioids combined with antidepressants or antiepileptic drugs for cancer pain: systematic review and meta-analysis. Palliat Med 2018;32(1):276-286

32 Kalso E, Tasmuth T, Neuvonen PJ. Amitriptyline effectively relieves neuropathic pain following treatment of breast cancer. Pain 1996;64(2):293-302

33 Finnerup NB, Attal N, Haroutounian S, et al. Pharmacotherapy for neuropathic pain in adults: a systematic review and meta-analysis. Lancet Neurol 2015;14(2):162-173

34 Steins MB, Eschbach C, Villalobos M, Thomas M. Pain in palliative care. Pneumologie 2017;71(5):297-306

35 Watson M, Lucas C, Hoy A, et al. Palliative Adult Network Guidelines. Northern Ireland: Sussex Cancer Network and Palliative Care Cymru Implementation Board; 2011

36 Miguel R. Interventional treatment of cancer pain: the fourth step in the World Health Organization analgesic ladder? Cancer Contr 2000;7(2):149-156

37 Wong FCS, Lee TW, Yuen KK, Lo SH, Sze WK, Tung SY. Intercostal nerve blockade for cancer pain: effectiveness and selection of patients. Hong Kong Med J 2007;13(4):266-270

38 Jackson MB, Pounder D, Price C, Matthews AW, Neville E. Percutaneous cervical cordotomy for the control of pain in patients with pleural mesothelioma. Thorax 1999;54(3):238-241

39 Baker L, Lee M, Regnard C, Crack L, Callin S; Tyneside Spinals Group. Evolving spinal analgesia practice in palliative care. Palliat Med 2004;18(6):507-515

40 O'Conner-Von S, Osterlund H, Shin L, Simpson MH, Integrative therapies used in pain management nursing. In: St. Marie BJ, ed. Core Curriculum for Pain Management Nursing. 2nd ed. Dubuque, IA: Kendall Hunt Publishers; 2010 307-318

41 Jang TK, Kim DY, Lee SW, et al. Trends in treatment during the last stages of life in end-stage gynecologic cancer patients who received active palliative chemotherapy: a comparative analysis of 10-year data in a single institution. BMC Palliat Care 2018;17(1):99

42 Young C, Lerman I, lyengar S, et al. Pain in central nervous system disorders. In: Gold MS, Pogatzki-zahn EM, Wallace MS, eds. Washington DC: IASP Press; 2018 135-145

43 Ulas S, Eyigor S, Caramat I. Quality of life and neuropathic pain in hospitalized cancer patients: a comparative analysis of patients in palliative care wards versus those in general wards. Indian J Palliat Care 2018;24(3):325-333

44 Saxena AK, Jain P, Dureja GP, et al. Pharmacological management of neuropathic pain in India. A consensus statement from Indian experts. Indian J Pain 2018;32(3):132-144

45 Cherny NI, Paluch-Shimon S, Berner-Wygoda Y. Palliative care: needs of advanced breast cancer patients. Breast Cancer (Dove Med Press) 2018;10:231-243

46 Buckholz GT, von Gunten CF. Nonpharmacological management of dyspnea. Current opinion in supportive and palliative care. 2009;3:98-102

47 Bove G, Naylor M, Busgnell MS, Complementary and integrative approaches for pain management. In: Gold MS, Pogatzkizahn EM, Wallace MS, eds. Washington DC: IASP Press; 2018 235-243

48 McDonald CF, Crockett AJ, Young IH. Adult domiciliary oxygen therapy. Position statement of the Thoracic Society of Australia and New Zealand. Med J Aust 2005;182(12):621-626

49 Abernethy AP, McDonald CF, Frith PA, et al. Effect of palliative oxygen versus room air in relief of breathlessness in patients with refractory dyspnoea: a double-blind, randomised controlled trial. Lancet 2010;376(9743):784-793

50 Cranston JM, Crockett A, Currow D. Oxygen therapy for dyspnoea in adults. Cochrane Database Syst Rev 2008

51 Bhatnagar R, Keenan EK, Morley AJ, et al. Outpatient talc administration by indwelling pleural catheter for malignant effusion. N Engl J Med 2018;378(14):1313-1322

52 Cross LA. Compassion fatigue in palliative care nursing: a concept analysis. J Hosp Palliat Nurs 2019;21(1):21-28

53 Merseyside and Cheshire Palliative Care Network Audit Group. Management of fatigue in palliative care patients. Expert Concensus;July 2009. Available at: https://www. nwcscnsenate.nhs.uk

54 Radbruch L, Strasser F, Elsner F, et al. Research Steering Committee of the European Association for Palliative Care (EAPC). Fatigue in palliative care patients-an EAPC approach. Palliat Med 2008;22(1):13-32

55 Jackson KC, Lipman AG. Drug therapy for delirium in terminally ill patients. Cochrane Database Syst Rev 2004; ( 2):CD004770

56 Bush SH, Lawlor PG, Ryan K, et al. ESMO Guidelines Committee. Delirium in adult cancer patients: ESMO clinical practice guidelines. Ann Oncol 2018;29(4Supplement_4 :iv143-iv165

57 Yennurajalingam S, Braiteh F, Bruera E. Pain and terminal delirium research in the elderly. Clin Geriatr Med 2005;21(1):93-119

58 Richardson P. Spirituality, religion and palliative care. Ann Palliat Med 2014;3(3):150-159

59 Walker A, Breitsameter C. The provision of spiritual care in hospices. A study in four hospices in north Rhine-Westphalia. J Relig Health 2017;56(6):2237-2250

60 Anandarajah G, Hight E. Spirituality and medical practice: using the HOPE questions as a practical tool for spiritual assessment. Am Fam Physician 2001;63(1):81-89

61 Reid CM, Forbes K. Pain in patients with cancer: still a long way to go. Pain 2007;132(3):229-230

62 Linklater GT, Leng ME, Tiernan EJ, Lee MA, Chambers WA. Pain management services in palliative care: a national survey. Palliat Med 2002;16(5):435-439

63 Kay S, Husbands E, Antrobus JH, Munday D. Provision for advanced pain management techniques in adult palliative care: a national survey of anaesthetic pain specialists. Palliat Med 2007;21(4):279-284

64 de la Cruz M, Reddy A, Balankari V, et al. The impact of an educational program on patient practices for safe use, storage, and disposal of opioids at a comprehensive cancer centre. Oncologist 2017;22(1):115-121 